\title{
Correction to: Cerebrospinal fluid levels of the neurotrophic factor neuroleukin are increased in early Alzheimer's disease, but not in cerebral amyloid angiopathy
}

Anna M. De Kort ${ }^{1}$, H. Bea Kuiperij ${ }^{1}$, Daniel Alcolea ${ }^{2,3}$, Iris Kersten ${ }^{1}$, Alexandra A. M. Versleijen ${ }^{4}$, Steven M. Greenberg ${ }^{5}$, Erik Stoops ${ }^{6}$, Floris H. B. M. Schreuder ${ }^{1}$, Catharina J. M. Klijn ${ }^{1}$, Alberto Lleó ${ }^{2,3}$, Jurgen A. H. R. Claassen ${ }^{7}$ and Marcel M. Verbeek ${ }^{1,4^{*}}$

Correction to: Alz Res Therapy 13, 160 (2021) https://doi.org/10.1186/s13195-021-00899-0

Following the publication of the original article [1] the authors noticed that the published Fig. 2 is incorrect. The authors uploaded the incorrect figure during the proofing process. The original article [1] has been updated. The correct Fig. 2 is depicted below.
Published online: 16 November 2021

\section{Reference}

1. De Kort AM, Kuiperij HB, Alcolea D, et al. Cerebrospinal fluid levels of the neurotrophic factor neuroleukin are increased in early Alzheimer's disease, but not in cerebral amyloid angiopathy. Alz Res Therapy. 2021;13:160. https://doi.org/10.1186/s13195-021-00899-0.

\begin{abstract}
Author details
'Department of Neurology, Radboud University Medical Center, Donders Institute for Brain, Cognition and Behaviour, Radboud Alzheimer Centre, P.O. Box 9101, 6500, HB, Nijmegen, The Netherlands. ${ }^{2}$ Sant Pau Memory Unit, Department of Neurology, Hospital de la Santa Creu i Sant Pau, Biomedical Research Institute Sant Pau, Universitat Autònoma de Barcelona, Barcelona, Spain. ${ }^{3}$ Center of Biomedical Investigation Network for Neurodegenerative Diseases (CIBERNED), Madrid, Spain. ${ }^{4}$ Department of Laboratory Medicine, Radboud University Medical Center, Nijmegen, The Netherlands. ${ }^{5}$ Department of Neurology, Massachusetts General Hospital, Harvard Medical School, Boston, MA, USA. ${ }^{6}$ ADx NeuroSciences, Ghent, Belgium. ${ }^{7}$ Department of Geriatrics, Radboud University Medical Center, Donders Institute for Brain, Cognition and Behaviour, Radboud Alzheimer Centre, Nijmegen, The Netherlands.
\end{abstract}

Full list of author information is available at the end of the article

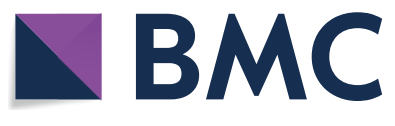

The Author(s) 2021. Open Access This article is licensed under a Creative Commons Attribution 4.0 International License, which permits use, sharing, adaptation, distribution and reproduction in any medium or format, as long as you give appropriate credit to the original author(s) and the source, provide a link to the Creative Commons licence, and indicate if changes were made. The images or other third party material in this article are included in the article's Creative Commons licence, unless indicated otherwise in a credit line to the material. If material is not included in the article's Creative Commons licence and your intended use is not permitted by statutory regulation or exceeds the permitted use, you will need to obtain permission directly from the copyright holder. To view a copy of this licence, visit http://creativecommons.org/licenses/by/4.0/. The Creative Commons Public Domain Dedication waiver (http://creativeco mmons.org/publicdomain/zero/1.0/) applies to the data made available in this article, unless otherwise stated in a credit line to the data. 


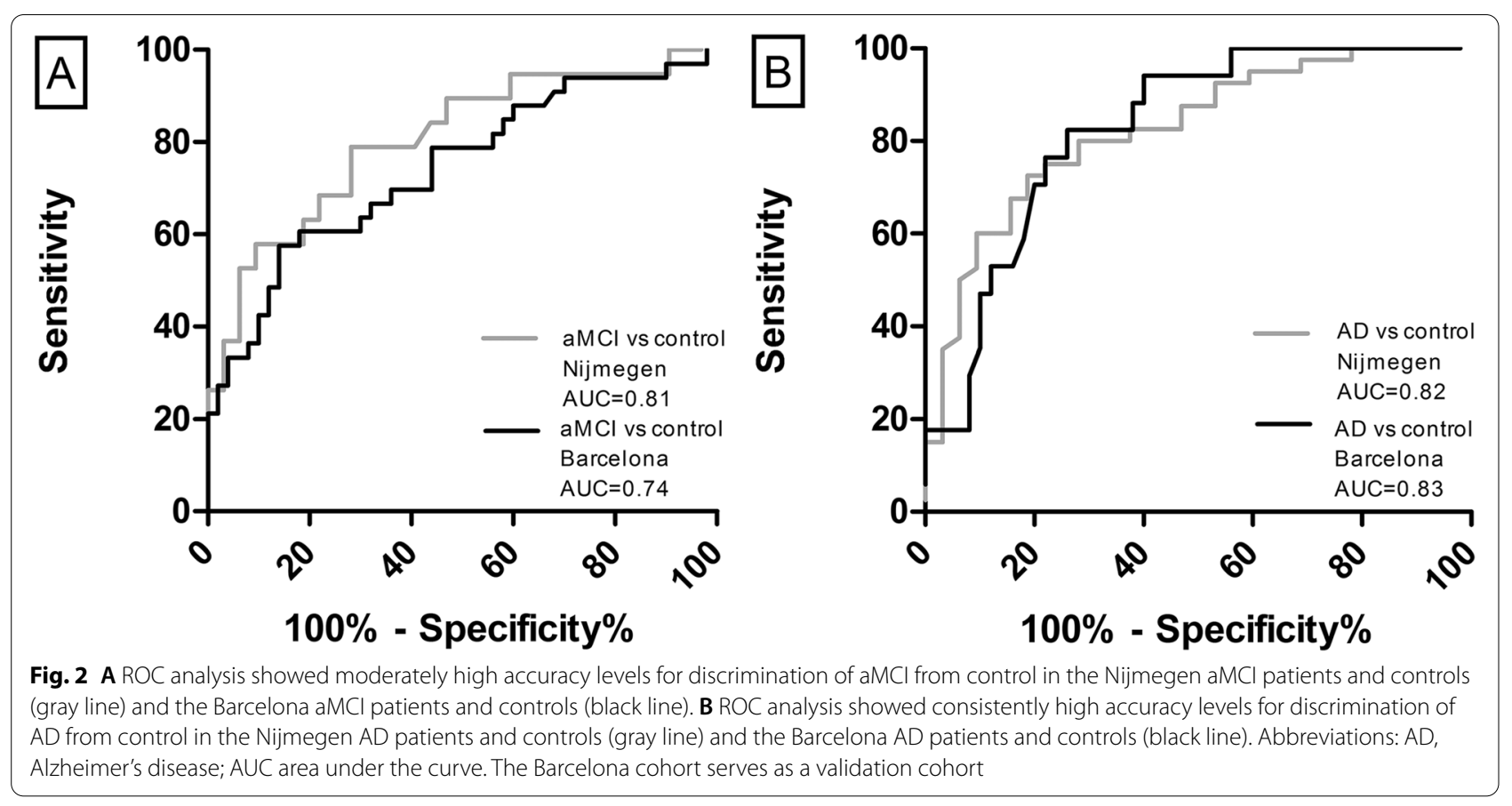

